University of Maryland Francis King Carey School of Law

DigitalCommons@UM Carey Law

$12-1-1990$

\title{
Gestational Surrogacy and the Health Care Provider: Put Part of the "IVF Genie" Back Into the Bottle
}

Karen H. Rothenberg

University of Maryland School of Law, krothenberg@law.umaryland.edu

Follow this and additional works at: https://digitalcommons.law.umaryland.edu/fac_pubs

Part of the Family Law Commons, Health Law and Policy Commons, and the Law and Gender Commons

\section{Digital Commons Citation}

Rothenberg, Karen H., "Gestational Surrogacy and the Health Care Provider: Put Part of the "IVF Genie" Back Into the Bottle" (1990). Faculty Scholarship. 155.

https://digitalcommons.law.umaryland.edu/fac_pubs/155

This Article is brought to you for free and open access by the Francis King Carey School of Law Faculty at DigitalCommons@UM Carey Law. It has been accepted for inclusion in Faculty Scholarship by an authorized administrator of DigitalCommons@UM Carey Law. For more information, please contact smccarty@law.umaryland.edu. 


\title{
Gestational Surrogacy and the Health Care Provider: Put Part of the "IVF Genie" Back Into the Bottle
}

\author{
Karen H. Rothenberg
}

\section{Introduction}

Medical advances in new reproductive technologies continue to raise complex legal and ethical issues. Last October, a California Superior Court judge issued his opinion on the first contested case in this country involving gestational surrogacy. ${ }^{1}$ Upholding the surrogacy contract as valid and declaring that the genetic parents had exclusive custody and parental rights, Judge Richard Parslow observed:

The IVF genie is out of the bottle and you're not going to be able to put it back. ${ }^{2}$

I contend that we must put part of the genie back into the bottle. Gestational surrogacy is not an acceptable option for the extension of in vitro fertilization (IVF). This is not a reaction to the facts of the California case, but rather a recognition that the medicalization of surrogacy as a reproductive technology attempts to legitimize a practice that professionals should not support.

Following a brief discussion of Johnsonv. Calvert, the recent California case, I will summarize the status of U.S. and international laws and policies on surrogacy, with particular attention to gestational surrogacy. I will also discuss recent ethical positions on surrogacy issued by health professional organizations. With this background established, I will outline my position on why the ethical and legal risks inherent in gestational surrogacy require professionals to reject it as a reproductive alternative.

An earlier version of this paper was presented at the International Symposium on the Beginning of Human Life, University of Iowa, November 4, 1990.

\section{The Johnson v. Calvert Case}

Crispina Calvert, who had had a hysterectomy, worked as a registered nurse in the same hospital as Anna Johnson, an ex-Marine, licensed vocational nurse. A mutual friend introduced them, believing that Anna had wanted to be a surrogate. Anna was black and a single parent of a threeyear old girl. She had had two prior miscarriages and two stillbirths. Crispina was Filipino and her husband, Mark, was white. The Calverts claimed that they could not afford to go to a surrogacy agency, but paid $\$ 3,500$ for the agency's standard contract and some legal advice. Johnson signed the contract. ${ }^{3}$

It is unclear whether Anna was ever screened as an "appropriate" surrogate. Crispina and Anna both began hormonal therapy to have their ovulation cycles mesh. Crispina had a number of eggs removed and fertilized with Mark's sperm and three were then transferred into Anna. Against the odds, one embryo implanted. For weeks, Anna received hormonal injections to maximize her chances of maintaining the pregnancy. Anna did have to be hospitalized more than once for complications during the pregnancy. She was also advised to seek psychiatric help for emotional problems. ${ }^{4}$

The deal seemed to be working. Anna would receive $\$ 10,000$ for her gestational services and for relinquishing the baby, the Calverts would have a genetic child, and the IVF program would contribute to another expansion of IVF for women who would otherwise not be able to benefit from such technology. But, Anna, for whatever reason, changed her mind and the deal began to fall apart. Seeking to invalidate the contract, she claimed among other things, that she had bonded with the fetus and sought the court's protection of her future parental rights. 
Unwilling to recognize the possibility of three parents and Anna's role as the gestational mother (and appearing to doubt her claim that she had, in fact, bonded), the judge declared the contract valid and granted full and exclusive custody to the Calverts. ${ }^{5}$ Anna Johnson filed an appeal on October 25, $1990 .^{6}$

\section{U.S. and International Developments}

Since the Baby $M$ case made headlines a few years ago, policies on surrogacy have continued to evolve around the world. ${ }^{7}$ In the United States, legislation has been introduced in Congress and in 39 states, as well as the District of Columbia, to deal with various aspects of commercial surrogacy. ${ }^{8}$ To date, only 13 states have passed laws dealing with surrogate parenting contracts and their legality. Eleven states have either declared commercial surrogacy illegal and/or made it impossible to enforce a contract as contrary to public policy. ${ }^{9} \mathrm{~A}$ few of these states specifically include gestational surrogacy within their definitional sections. ${ }^{10}$ Arkansas allows for a birth certificate to be changed to recognize that the intended mother rather than the surrogate is the legal mother, but is vague about the parameters of the legality of surrogacy. ${ }^{11}$ New Hampshire's recent statute permits, but with extensive regulation and pre-approval by the court, both forms of surrogacy. ${ }^{12}$ No statute gives more rights to the surrogate with a genetic connection than to the gestational surrogate. ${ }^{13}$

Bioethical task forces in both New Jersey and New York have also recommended that surrogacy not be allowed, particularly in the commercial setting, and that the surrogate be given the right to keep the child. ${ }^{14}$ In fact, the New Jersey Task Force recommends that it be criminal for professionals to participate in commercial surrogacy. The prohibition can subject the professional to a charge of unprofessional conduct and prosecution. Such participation in surrogacy might include screening of candidates and performing artificial insemination and embryo transfer with a gestational surrogate.

Most recently, California's Joint Legislative Committee on Surrogate Parenting recommended that commercial surrogate mother agreements be void and unenforceable. Furthermore, the Committee advised that California law should provide that "when ova or embryos have come from a woman other than the one who gives birth, the gestating woman is irrebuttably presumed to be the natural mother."15

Internationally, laws and policies clearly establish that surrogacy contracts, especially if commercial, are illegal, unenforceable, contrary to public policy and/or void. ${ }^{16}$ Furthermore, most laws establish that the birth mother is deemed the legal mother. ${ }^{17}$
Of particular interest, Bulgaria declares that motherhood is determined by birth, whether or not conception is with another's genetic material. ${ }^{18}$ Israeli regulations establish that a fertilized egg may only be implanted in the intended mother. ${ }^{19}$ In Norway and Sweden, a fertilized egg may only be placed back into the woman from whom the egg was removed..$^{20}$ In Spain, surrogacy with or without money is null and void, but if there is a contract for gestation, it declares that the mother who gave birth is still the mother. ${ }^{21}$ The United Kingdom bans commercial surrogacy agencies from engaging women to act as surrogate mothers ${ }^{22}$ and the German Parliament just passed a law banning both surrogate motherhood and embryo transfer. ${ }^{23}$

The Council of Europe has declared that "maternity should be determined by the fact of giving birth, rather than genetics (origin of the ova), firstly because of the relationship between the child and the woman giving birth and, secondly, because of the necessity of giving the child a clear legal situation at birth." ${ }^{24}$ Furthermore, absent an exceptional case, surrogate motherhood should be banned and such contracts should be deemed null and void. ${ }^{25}$ The Council cautions that physicians should be prohibited from bringing together an infertile couple and a surrogate mother. ${ }^{26}$

Health professional organizations both in the United States and abroad have also taken positions. The American Medical Association in December of 1988 incorporated its earlier report on surrogacy into its official Opinions of its Council on Ethical and Judicial Affairs. The opinion states that surrogacy, whether genetic or gestational, "does not represent a satisfactory reproductive alternative for people who wish to become parents." ${ }^{27}$ This past June, the Ethics Committee of the American Fertility Society also reissued, with minor changes, its position recommending that surrogacy and gestational surrogacy be continued as only a "clinical experiment." 28

The Committee on Ethics of the American College of Obstetrics and Gynecology (ACOG) just issued its revised opinion on "Ethical Issues in Surrogate Motherhood."29 The Committee found that the surrogate who both carries the fetus and delivers the infant should be the sole source of consent for all questions regarding prenatal care and delivery and that she should have a specified time after birth to decide whether or not to place the child for adoption with the commissioning couple. The opinion specifically addresses, in part, gestational surrogacy and recognizes that while the genetic link to the couple is important, it deems it "less weighty than the link between the surrogate mother and the fetus or infant that is created through gestation and birth." ${ }^{30}$ Thus, the opinion makes no ethical distinction between what it describes as "the usual pattern of surrogate parenting and surrogate gestational motherhood." 31 


\section{Law, Medicine \& Health Care}

The ACOG Committee further states that the physician, when approached, should assure all disclosure of medical and ethical risk and that the provider may justifiably decline to participate in a surrogacy arrangement. If the physician does agree to participate, strict ethical guidelines should be followed. Of particular interest is that the surrogate and the commissioning couple should be regarded as distinct parties and should be separately represented, both medically and legally. ${ }^{32}$

In August 1990, the Working Party on Human Infertility Services of the British Medical Association (BMA) adopted extensive ethical guidelines on surrogacy. ${ }^{33}$ These guidelines supersede a 1987 ruling that doctors should not take part in surrogacy arrangements until the BMA had agreed upon ethical controls. ${ }^{34}$ The BMA guidelines warn physicians that surrogacy arrangements are unenforceable in law and that either of the parties cannot be prevented from breach. ${ }^{35}$ The guidelines provide that surrogacy be a last resort, that doctors only consider as surrogates those women who have a partner and already have one child. Physicians should also warn both the commissioning couple and the surrogate and her partner of all risks (which the BMA outlines in great detail), including the possibility that the surrogate may refuse to relinquish the child and that the commissioning couple may refuse to accept a child born with any defects. ${ }^{36}$ The Working Party makes no ethical or legal distinction between genetic and gestational surrogacy. In fact, they note that "whatever the genetic origins of a child, and regardless of the wishes of the participants, the law regards the child as belonging to the mother who delivered it." 37

\section{The Gestational Surrogacy Process: Ethical and Legal Problems}

The American College of Obstetrics and Gynecology and the British Medical Association both have accepted the political reality that infertility specialists fear restrictions on their practice. In fact, some IVF programs are acting to create increasing demand for legalized surrogacy. Surrogacy in this medical context reduces gestation to a technological tool. This is understandable considering the increasing expectation of the couple believing that with enough technology anyone can have a baby.

At the same time this medicalization reduces the role played by the gestational mother in the creation of life. The surrogate is deemed to be making a healthy adjustment if she remains unconnected-the most unnatural of feelings. Reducing women to extensions of a medical process in this manner can lead to numerous dangerous consequences.

Furthermore, as an international matter, gestational surrogacy has the potential to exploit poor women from Third World countries, who may be desperate for money, and perhaps harbor the false hope of immigrating to the United States. Rich white couples, in turn desperate for a genetic connection, can use poor women to achieve their wishes. Health care professionals cannot condone using women in this way.

I would strongly urge health professionals to resist any support of the use of a gestational surrogate. Obviously we all want to satisfy the infertile couple with the option of IVF. But we have to set limits when another woman, also being treated as a unit by the IVF program, is involved. We are pitting mothers against each other and potentially the health care provider is in the middle of the conflict. The right law, the right contract, and the right counseling will not be able to correct the problems with gestational surrogacy..$^{38}$

I do not make this argument in defense of Anna Johnson, or in reaction to that case. Although I am surprised that we have not seem more cases yet, they will come and the health care provider will be in a no-win position..$^{39}$ In the following sections this paper will highlight the specific issues that gestational surrogacy poses for the health care professional throughout the process.

\section{Screening}

Proponents of surrogacy believe that with enough screening by qualified professionals, surrogacy can be a success. The recent New Hampshire statute, ${ }^{40}$ in fact, provides for professional screening of both the couple and the surrogate to assure a court in a pre-approval process that the contract will work. Yet what are we screening for?

For example, how does a psychologist assess whether a gestational surrogate is a good risk ${ }^{41}$ If she is less willing to want to bond because there is no genetic connection, will she remain this way throughout the gestational process? And what if she does continue to feel removed, because there is no genetic connection? Will this influence her prenatal behavior and make her a bad risk and a noncompliant patient? The data does not exist to develop the perfect profile of the surrogate and the commissioning couple who can cope with IVF and embryo transfer. What are the measures of motivation, self-esteem, family support, and experiences with coping with childbearing loss? What relationship will the genetic and the gestational mother have to each other? What perception does the surrogate have of the father and the future of a unit relationship? Certainly we do not have experience with genetic parents dealing with loss to the gestational mother.

We do have some experience that supports the motivation to deny or omit feelings and relevant medical information. And there may be even an unconscious 
motivation not to hear or appreciate all the risks when the motivation is so strong to achieve a pregnancy for the couple, the IVF program, and for the surrogate to be successful and to be paid.

In the first medical malpractice case filed that involved the treatment of a surrogate, Mounce $v$. Hanson, ${ }^{42}$ the surrogate did admit to the physician who took her medical history that she had had two prior miscarriages and no live births. She was not screened out. Perhaps more importantly, she did not state that she had had a history of heart trouble. She was desperate to serve as a surrogate, perhaps as a way to deal with her prior losses, and to make some money. In her eighth month of pregnancy, she died of heart failure, following a number of warning signals, and the baby died too. The sperm donor never came forward, but her family has sued Genesearch, the surrogacy program, the physician who screened and provided her prenatal care, and the consulting cardiologist. ${ }^{43}$

The Calverts also claimed that Anna Johnson failed to provide them with important medical information. She did not reveal that she had had two miscarriages and two stillbirths. ${ }^{44} \mathrm{Clearly}$, she was not an ideal candidate, either medically or psychologically, for a surrogacy deal. When money is involved and when we all want something badly enough, screening may be of limited use without all the facts. And even if we think we have all the facts, we have to decide which facts are the ones that matter.

Thus, in spite of the call for screening to assure that the deal has the "Good Housekeeping seal of approval," the process is flawed. First of all, we have no consensus on what we are screening for. Medically, what are the standards for an acceptable surrogate? The existence of a uterus and a willing carrier is not good enough. Rather, I would argue that at the present time an infertile couple is not a candidate for IVF if the woman is not able to be the birth mother. As noted earlier, Norway, Sweden and Israel require that IVF only be allowed if the woman is implanted with her own genetic material. ${ }^{45}$

Secondly, we do not know what the acceptable psychological profile is for a low risk couple and surrogate. And finally, professionals are not qualified to determine what information is meaningful. The ethical and legal, not to mention medical and psychological risks, are not clear, and by definition, they may never be.

\section{Informed Consent}

Assuming that both the couple and the surrogate pass the screening requirements, an elaborate informed consent process is to follow. ACOG, for example, recommends that the medical and ethical risks be carefully spelled out to the couple and the surrogate. ${ }^{46}$ The New Hampshire statute also requires an extensive evaluation, counseling, and informed consent process. ${ }^{47}$ But are health care providers qualified to do the job? And do they have enough information to make the process meaningful? How does a gestational surrogate consent knowingly to relinquishment of a future child? She may have experienced a birth, but is it easier or harder to relinquish if you have no genetic connection? Is the lack of a genetic connection relevant at all? Obviously, genetics matter to the couple, who may feel more strongly about losing their wholly genetic child.

In fact, how does a provider describe the ethical and legal risks? Legally, less than a quarter of the states have laws that either hold surrogacy contracts unenforceable or heavily regulate it. ${ }^{48}$ Under traditional family law, rather than contract law, the birth mother is the mother. Yet, in Johnson v. Calvert the lower court in California found that genetics was all that mattered and the gestational mother had no rights. ${ }^{49}$

Clearly, informed consent based on legal risks is risky at best. There are no guarantees. Nor are there any guarantees with respect to psychological risk for the couple, the surrogate, or the surrogate's family. Medically, there are unknown long-term risks associated with fertility drugs, IVF procedures, risk to the child, and risks to the gestational surrogate from multiple gestation. Obviously, the medical risks are more significant for the gestational surrogate than for the surrogate who is just artificially inseminated and usually carries just a single fetus to term. Again, it is one thing to risk your own body. It is quite another to achieve "voluntary" consent to experiment with another woman's body for the couple's benefit.

\section{Conflict of interest and the embryo transfer}

Assuming some form of informed consent is attempted, there still remain problems with the inherent conflict of interest of the IVF program promoting embryo transfer with a gestational surrogate. The couple and surrogate are treated like a unit with the same interest - the achievement of a successful pregnancy. The client though, is not the surrogate, but the paying couple. The surrogate is needed to allow the provider to extend the potential of IVF use into a "uterine carrier." The surrogate is a means to an end. How can the physician maintain a confidential relationship with two women who both are potential mothers of the same baby or babies?

Furthermore, the medical risks are significant for both the genetic and gestational mother. First the ovulation cycles must coincide. Drugs are necessary to manipulate their cycles. Fertility drugs also help stimulate the production of eggs for the genetic mother-to-be so that a number of eggs can be retrieved. This woman is clearly 


\section{Law, Medicine \& Health Care}

risking a lot to make the process work. The egg is then fertilized with the husband's sperm and any resulting embryos are transferred into the gestational surrogate. The surrogate continues on hormonal injection for a number of weeks to maximize the chances of a successful implantation and pregnancy. The IVF program has a responsibility to the well-being of all members of this unit.

This is a risky business. Once the IVF process is finished, the IVF program may think its job is over. A pregnancy (or pregnancies) has been achieved, yet there is potential for future maternal morbidity and mortality for both mothers-to-be. It is one thing to assume these risks when the genetic mother is to also be the host uterus. It is different however, when there is potential for conflict within the unit. In fact, all the parties cannot be treated as a unit. They are individual patients, with individual needs, and the provider must avoid all appearances of any conflict of interest. By its very definition, IVF and embryo transfer with a gestational surrogate is a case of potential conflict of interest. The ACOG Committee Opinion states conflict of interest must be avoided by the use of separate medical providers for infertility and care to the surrogate. $^{50}$

For the process to work, will we tolerate inherent conflict which clearly favors the interests of the consumers of the IVF technology over the surrogate? Does the IVF provider have, in fact, a physician-patient relationship with the surrogate, or does the provider take the surrogate as a mere extension of the procedure? How much responsibility will the IVF program take for screening a surrogate? If the surrogate is good enough for the couple, is the surrogate good enough for the IVF provider? It is the responsibility of the provider to warn the surrogate of all risks, but is not this then in conflict with the couple's goals and interests?

The ACOG Committee Opinion provides that the surrogate is the source of all medical decisions with respect to the pregnancy. ${ }^{51}$ For in fact, once the transfer is complete, all biological connections are made by the gestational mother-to-be. She is more than a uterine container. ${ }^{52}$ She provides all the nutrients and bodily functions necessary to make this embryo grow into a fetus and then a baby. Clearly the interest of all is in her physical and emotional well-being. And any psychological counseling necessary during pregnancy must be directed to doing what is best for the pregnant woman.

\section{Multiple embryo transfer}

It is common IVF practice to transfer at least three fertilized embryos. Some IVF programs transfer up to six. ${ }^{53}$ Obviously, this practice attempts to maximize the chances of achieving a pregnancy. However, the chances of twins, triplets and maybe more are not remote. A recent World Health Organization study on IVF found that with the potential for multiple birth, maternal morbidity and mortality as well as infant morbidity and mortality significantly increase. ${ }^{54}$ If the genetic mother chooses to take this risk with her body, it is one thing. But health care professionals should not be imposing such risks on the gestational surrogate whose body is being used for the couple's benefit.

Multiple gestation and its risks raise problems for gestational surrogacy that were not considered with genetic surrogacy in which single gestation is the norm. The risks to all parties, including the liability of the IVF physician, increase. It is more likely that the gestational surrogate will become a high risk pregnancy, will require a cesarean section delivery, will have more complications, more monitoring, and be unable to continue working throughout the pregnancy. And how do we then fairly compensate for this additional burden of gestational service and relinquishing more than one baby?

The potential conflict of interest for the IVF provider appears again. Just how many embryos are right to transfer? On the one hand, selective termination of the "extras" might be the answer for the genetic couple. 55 This way they can choose two and let the rest go. But what about the surrogate's view? Perhaps she will not want to abort and will risk carrying all three or four to term. Of course, this decision also raises the risk to her and the fetuses.

Ultimately, if the gestational surrogate is the decisionmaker for medical care, she and not the genetic couple must decide what is best for her health and the health of the fetuses, including selective termination of pregnancy. This is not to say that the couple and provider will not exert a lot of pressure on her.

\section{Prenatal diagnosis and genetic testing}

A standard surrogate contract will require the surrogate to undergo genetic testing, including amniocentesis to establish whether or not there are any genetic or chromosomal abnormalities. Yet is not this a strange requirement for the gestational surrogate? The gestational surrogate is being asked to undergo such procedures, when she is not the genetic carrier of the problems being screened for. Obviously genetic counseling has no function for her. Such counseling is relevant to the genetic couple, but it is the surrogate who is subjecting herself to the testing. Once again she would have the right not to abort a defective fetus, but if the couple then rejects the fetus, who gets the child? Unless the surrogate chooses to keep the child with no genetic link to her, the child may become a ward of the state. What if she does choose to abort the fetus, because 
she does not want to carry a "defective" pregnancy, and the couple still wants the pregnancy to continue? It is the couple's genetic material and they are willing to accept the result. Yet, if they desire the surrogate to have genetic testing, it would seem that the couple would have to accept her decision to abort. Regardless of the result, the use of genetic testing with gestational surrogates raises unique ethical and legal challenges for the provider.

\section{Control of behavioral lifestyle and work environment}

In addition to genetic testing, surrogate contracts often require that surrogates do not drink, smoke, or take illicit drugs. Enforcement of such provisions is problematic. They require that the physician take on the role of spy, rather than the fiduciary role to the patient. In fact, the ACOG Committee Opinion clearly provides that the confidential relationship remains with the surrogate. ${ }^{56}$

However, with gestational surrogacy, it would seem that the couple, and perhaps the physician, will feel more need to control the gestational surrogate. If she is less attached, since she has no genetic connection, they may fear she will be less concerned with taking care of herself and the fetus. There have been cases in which health care providers have gone to court to try to force certain treatments, or cesarean section deliveries. ${ }^{57}$ Although it may seem unlikely, the couple, with the support of the provider, after investing so much time, emotional energy, and money in achieving a pregnancy, may feel they have no other recourse than to go to court to attempt to protect their genetic material from any negative behaviors of the surrogate. The couple might try to argue that their intention to rear the child, as well as the force of the contract, gives them legal standing to seek an injunction to get the surrogate to undergo a medical procedure or to stop smoking, drinking, or taking drugs during the pregnancy. It is not clear whether the court would be more or less concerned about the autonomy of the pregnant woman to control her own body when she does not have the intention to bear the child and accept the consequences of her actions. One also wonders what the psychological impact of not carrying a genetic fetus has on the acts and behavior of the surrogate, as well as on the health of the uterine environment. If in fact, it is easier to separate, is it easier to ignore other concerns for the fetus?

Furthermore, what will be the implications for employment of the surrogate? Is gestating her only job? Does she have the right to continue any other employment? If she works in a lead factory, must she be forced to be transferred or fired? ${ }^{58}$ What if she is having twins and is told "to get off her feet?" If she stops working, will the couple pay her lost earnings? Will she be barred from disability payments if pregnancy resulted from an embryo transfer for hire? What role will the provider play in helping her to obtain disability coverage? With the increase in medical risk comes increasing economic risk.

\section{Birth defects and causation}

Unfortunately, no one can guarantee the birth of a healthy child. With gestational surrogacy, it may be more difficult to determine the cause of a problem at birth. Was it a genetic problem? Was it the work environment that the surrogate worked in? Was it the one drink? Was it caused by a sexually transmitted disease that she caught during relations with her husband? Gestational surrogacy takes genetics out of the picture, but it may be difficult to pin the problem on a particular cause. In the end, will the couple and/or the surrogate, if she retains custody, look to the physician for a financial solution through a liability claim? With so much that cannot be controlled in the birth process, and with such high expectations and expenses generated from IVF and embryo transfer, a liability threat from both the surrogate ${ }^{59}$ and commissioning couple should not be minimized.

\section{Conclusion}

State courts and legislatures, health professional organizations, and policymakers throughout the world are struggling to develop laws and guidelines to address the complex questions raised by the expansion of new reproductive technologies. Clearly, infertility specialists are sincerely devoted to trying to help couples have their own babies. But health care professionals must resist the temptation to expand the use of IVF and embryo transfer with gestational surrogacy. The medical, ethical and legal risks of using another woman to serve the interests of the infertile couple cannot be minimized. Gestational surrogacy is not a cure for infertility, but rather a course to be avoided.

\section{References}

1. Johnson $v$. Calvert, No. 63-31-90 (Orange Cty. Super. Ct. Calif. October 22, 1990). Gestational surrogacy is used in combination with in vitro fertilization. The fertilized egg of the genetic mother with the sperm of the genetic father or a sperm donor in vitro is transferred into the uterus of the surrogate, who is the birth mother. This differs from what I will term "genetic surrogacy" in which both the egg and gestation are provided by the surrogate, as was the case with Mary Beth Whitehead. Since the first birth in 1986, there have been about 80-100 births by gestational surrogates in this country. (cite) Non-commercial gestational surrogacy is also practiced at Bourn 


\section{Law, Medicine \& Health Care}

Hall Clinic, Britain's leading IVF clinic near Cambridge, England. See The Sunday Times, Aug. 19, 1990.

2. Id.

3. Facts reported in The Los Angeles Times, October 23, 1990, Part A, p. 1, col. 5.

4. Additional facts about the case provided through personal interviews with the lawyers for Anna Johnson and the Calverts (October 1990).

5. Johnson v. Calvert, No. 63-31-90 (Orange Cty. Super. Ct. Calif. October 22, 1990).

6. See The National Law Journal, November 5, 1990, p.36.

7. Since the New Jersey Supreme Court declared the surrogacy contract unenforceable in In re Baby M, 109 N.J.396, 537 A.2d 1227 (1988), I have been cautioning health professionals to seriously consider the unanswered ethical and legal questions raised by surrogacy. See, e.g., Rothenberg, "Surrogacy and the Health Care Professional: Baby $M$ and Beyond," in Gostin (ed.), Surrogate Motherhood: Politics and Privacy (Ind. Univ. Press 1990).

8. See, e.g., Adams, "State Legislative Report: Surrogate Parenting Contract Legislation Enacted: 1987, 1988 and 1989 Legislative Sessions," National Conference of State Legislatures Vol.15, No. 2(1990). See also “1990 Update"(July 1990).

9. Id. Arizona (1989 Ariz. Sess. Laws 14); Florida (Fla. Stat. Sec. 63.212(1) (1988) although allowing for preplanned adoption arrangements with specific terms); Indiana (Ind. Code Sec. 31-8-2-1 - to 31-8-2-3) (1988) sets out rights for the surrogate if an agreement is entered into; Kentucky (Ky. Rev. Stat. Sec. 199.590 (1988); Louisiana (La. Rev. Stat. Ann. Sec. 9:2713 (1987); Michigan (Mich. Comp. Laws, Sec. 722.851722.863 (1988); Nebraska (Ne. Rev. Stat. 674 (1988); Nevada (Nev. Rev. Stat. 127.303.5 (1987); North Dakota (1989 N.D. Sess. Laws 184); Utah (1989 Utah Laws 140); Washington (1989 Wash. Laws 404).

10. Louisiana and Kentucky just discuss surrogacy by insemination, with no discussion of gestational services and/or surrogacy by embryo transfer.

11. 1989 Ark. Acts 647.

12. New Hampshire, HB-1426-FN, Chapter 87(1990).

13. The Uniform Status of Children of Assisted Conception Act, drafted by the National Conference of Commissioners on Uniform State Laws (1988), provides for one alternative that declares surrogacy contracts unenforceable (the alternative adopted by North Dakota) and it establishes that the birth mother is the legal mother. The other alternative, not adopted by any legislature, does provide that a surrogate who also provides the egg can change her mind within 180 days after the last insemination, but makes no similar provision for the gestational surrogate. There is no discussion on why the distinction was made, but this provision was a major political compromise.

14. See New York State Task Force on Life and the Law, Surrogate Parenting: Analysis and Recommendations for Public Policy, (New York May 1988); New Jersey Task Force on New Reproductive Practices, "Policy Recommendations on Surrogacy" (New Jersey July 1990).

15. The Committee did conclude that voluntary, unpaid, surrogate parenting arrangements should be allowed and should proceed consistent with other adoption practices. "Commercial and Noncommercial Surrogate Parenting," Report of the Joint Legislative Committee on Surrogate Parenting to the California State Legislature 22 (Nov. 1990).

16. See generally Stepan (ed.), International Survey of Laws on Assisted Procreation (Zurich 1990) (hereinafter "Survey"). The Ontario Law Reform Commission and a recent Australian National Bioethics Consultative Committee report do recommend limited approval and strict regulation of supervised, non-commercial surrogacy contracts.

17. See Survey, supra note 16.

18. Bulgaria Family Code, Art 31 (May 1985), reprinted in Survey, supra note 16 at 95.

19. Israeli Public Health (In Vitro Fertilization) Regulations, Ministry of Health (1987) at sec. 11, reprinted in Survey, supra note 16 at $121,124$.

20. Norwegian Law on Artificial Fertilization, No. 68, Chapter III (1987), reprinted in Survey at 139, 141; Swedish Law on Fertilization Outside the Human Body, No. 711, at 2 (1988), reprinted in Survey, supra note 16 at 172.

21. Spanish Law on Assisted Reproduction Procedures, No. 35/1988, Chapter 10 (1988), reprinted in Survey, supra note 16 at 157,161 .

22. United Kingdom Surrogacy Arrangements Act (1985), reprinted in Survey, supra note 16 at 184.

23. See Reproductive Rights Reporter, Vol. II, No. 19 at 8 (Oct. 26, 1990).

24. Council of Europe, Human Artificial Procreation, Principle 14 at 28-29 (Strasbourg 1989).

25. Id. Principle 15 at 29-30.

26. Id.

27. Opinions of the A.M.A. Council on Ethical and Judicial Affairs (Dec. 1988).

28. Ethics Committee of the American Fertility Society, Ethical Considerations of the New Reproductive Technologies, "Surrogate Gestational Mothers" (Chapter 21 at 64S-67S) \& "Surrogate Mothers" (Chapter 22 at 68S-73S), 53 Fertility and Sterility (1990).

29. American College of Obstetrics and Gynecology, Committee on Ethics, "Ethical Issues in Surrogate Motherhood," No. 88 (Nov. 1990)(hereinafter “ACOG Committee Opinion").

30. Id. at 2 .

31. Id.

32. Id. at 4-5.

33. British Medical Association, "Surrogacy: Ethical Considerations-Report of the Working Party on Human Infertility Services" (Aug. 1990) (hereinafter "BMA").

34. In fact, the Swiss Academy of Medicine continues to express general hostility to the use of IVF and embryo transfer in conjunction with surrogacy.

35. BMA, supra note 33 at 28 . See Human Fertilization and Embryology Law (1990).

36. BMA, supra note 16 at $28-30$.

37. Id. at 41 .

38. Many of the problems are inherent in noncommercial, as well as commercial surrogacy. For an outstanding discussion on why noncommercial surrogacy cannot be treated as a "mere act of altruism" and why reproductive gift-giving 
must be critically evaluated in the context of women's political inequality, see Raymond, "Reproductive Gifts and Gift Giving: The Altruistic Woman," Hastings Center Report 7 (Nov./Dec. 1990).

39. There are at least five other cases pending in lower and appellate courts around the country, according to Sharon DeAngelo, co-founder of the Washington, D.C.-based National Coalition Against Surrogacy. The National Law Journal, Oct. 8, 1990. See also, infra note 59 for discussion of tort actions by Anna Johnson and Mary Beth Whitehead. (1990).

40. HB 1426-FN, New Hampshire Laws, Chapter 87

41. See generally Harrison, "Psychological Ramifications of 'Surrogate' Motherhood," in Scotland (ed.), Psychiatric Aspects of Reproductive Technology 97 (1990).

42. No. 89-045388 (Harris Cty. Tex. 1990).

43. Id. Follow up discussions with the attorneys representing the estate of Ms. Mounce and Dr. Hanson (October 1990).

44. Numerous newspaper accounts of the testimony and discussions with the lawyers state that this information was not shared. In fact, the court opinion notes that "the Calverts were relying on Anna's representations, and arguably omissions, because there are some things she didn't tell them about her experience." The National Law Journal, Nov. 5, 1990, p.36.

45. See supra notes 19-20 and accompanying text.

46. ACOG Committee Opinion, supra note 29 at 4-5.

47. HB 1426-FN, New Hampshire Laws, Chapter 87 (1990).

48. See supra note 9 and accompanying text.

49. See supra note 1 . The appeal was filed to the 4 th District Court of Appeals on October 25, 1990.

50. See ACOG Committee Opinion, supra note 29 at 5. The Committee did not specifically address the inherent conflict of interest of the IVF program provider at the time of embryo transfer. Discussion with Elaine Locke, staff to ACOG Committee on Ethics (October 1990).

51. Id.

52. The more we view her as a container, the more we also separate her interests from those of the fetus, rather than seeing them as a union growing together.

53. See, e.g., Wagner, "Is In-Vitro Fertilization Appropriate Technology?" (World Health Organization 1989), reported in The Age, May 15, 1989, p. 1.

54. Id.

55. For a discussion on the difficult issues raised by selective termination, see Overall, "Selective Termination of Pregnancy and Women's Reproductive Autonomy," Hastings Center Report 6 (May/June 1990).

56. ACOG Committee Opinion, supra note 29 at 4-5.

57. See Kolder, et al., "Court-Ordered Obstetrical Interventions," 316 New England Journal of Medicine 1192, No. 19 (May 1987); In re A.C., 573 A.2d 1235 (D.C. App. 1990).

58. See generally, International Union UAW v. Johnson Controls, Inc., 886 F.2d 871 (7th Cir. 1989), cert. granted 110 S.Ct. $1522(1990)$ in which the Court will determine in part whether an employer's fetal protection policy in the workplace violates sex discrimination law.

59. In fact, Anna Johnson filed a complaint last December against the physician who performed the IVF procedure, the IVF program, and the attorney who drafted the surrogacy contract. The claims against the physician, for example, include allegations of medical malpractice, failure to provide informed consent, battery, and negligent and intentional infliction of emotional distress (discussion with Richard Gilbert, attorney for Anna Johnson, January 8, 1991). A few years earlier, Mary Beth Whitehead settled out of court her action against Noel Keane and the Infertility Center of New York for fraud in the Baby $M$ contract and for their failure to properly counsel her on the risks of surrogacy. 